\title{
Living with Flood: A Livelihood Resilience Approach of Rural People in Bihar, India
}

\author{
Madhuri \\ Department of Humanities and Social Sciences, IIT Kharagpur \\ Kharagpur, West Bengal 721302, India \\ Email: madhuriptp09@gmail.com,madhuri@iitkgp.ac.in \\ H. R. Tewari \\ Department of Humanities and Social Sciences, IIT Kharagpur \\ Kharagpur, West Bengal 721302, India \\ Email:hrt@hss.iitkgp.ernet.in \\ P. K. Bhowmick \\ Rural Development Centre, IIT Kharagpur \\ Kharagpur, West Bengal 721302, India \\ Email: pradipb@hijli.iitkgp.ernet.in
}

Received 2 December 2015

Accepted 12 April 2016

\begin{abstract}
Flood is a perennial problem in the state of Bihar, India with devastating impact on the livelihood of people. In spite of the government's measures of flood mitigation, households continue to live with sufferings on account of severe damage to their material and non-material assets. In this background, the objectives of the study are (1) to assess the mediating role of risk perception, and flood preparedness between flood experience and livelihood resilience; and, (2) to assess the mediating role of risk perception, and flood preparedness between flood education and livelihood resilience. The primary data were collected from 472 households by using multi-stage random sampling technique from seven blocks in river basins of Ganga and Kosi in the district of Bhagalpur, Bihar. To analyze the data descriptive statistics and structural equation modelling were used. However, risk perception is not found to mediate between flood experiences, flood education, and livelihood resilience. Households adapt the strategy of 'wait-watch-act'. Households do not perceive flood as a threat but they have learnt to 'live with flood' as a 'way of life'. The study recommends that the active involvement of the local people can be made mandatory with due consideration to their indigenous knowledge, flood experience, and flood education in order to make flood measures effective and successful.
\end{abstract}

Keywords: Flood, vulnerability, resilience, livelihood, household

\section{Introduction}

The inundation of a vast area of land and the resultant loss of property, human lives, and livelihood of households by recurring river flood is the most challenging phenomenon in the agrarian state of Bihar, India. The livelihood structure created after years of hard work by households is lost in no time, and its restoration takes longer than the expected time depending on pace and expediency of the relief assistance received from the government as well as non-governmental organizations. However, it is primarily the resilience measures of the local community (Saavedra and Budd, 2009) that matter the most and hence, ought be placed centrally and enhanced further (Srivastava and Laurian, 2006) in strategic interventions to cope with and recover from the shocks caused by flood (Bosher et al., 2009).

Flood, all its devastating effects, severely jeopardizes the livelihood of people who live in active zone of flooding. The livelihood structure created after years of hard work is suddenly washed away in no time. Households adapt strategies to 
reconstruct their livelihood structure according to their capability, adaptability, in view of their experience and knowledge and with the support they receive from their own community, the government, and other external agencies including NGOs. The government's approach to livelihood includes both structural as well as non-structural measures. Included in the structural measures are construction of dams, floodwall, and levee, while in non-structural measures, regulations, zoning, and protecting floodplains and wetlands are included (Heidari, 2009). Nevertheless, these measures neither succeed in checking flood damages, nor address the related issues of water logging and drainage congestion (Vari and Ferencz, 2006). Failure of these measures brought in focus on reducing vulnerability, and thereafter resilience building of the affected households was accorded prominence in flood mitigation measures (Hyogo Framework for Action 2005-2015: Building the Resilience of Nations and Communities to Disasters). Timmerman (1981) in his paper 'Vulnerability, Resilience, and the Collapse of Societies' introduced the term 'Resilience', i.e., capacity to absorb, resist and recover from disaster (Klein et al., 2003). Tierney and Bruneau (2007) stated that 'resilience building' is key to livelihood because (1) it nurtures and enhances the ability of social and physical systems to absorb, resist and recover from disaster; (2) the pre and post measures to mitigate disaster help in reducing harms it might cause (Maguire and Hagan, 2007; Tierney and Bruneau, 2007); (3)resilience building is an important trait for both the social and physical systems which support sustainability (Tierney and Bruneau, 2007); (4)it increases the capability in dealing with uncertainties and unexpected changes (Berkes, 2007); (5)the measures of resilience building are proactive and emphasize on the collective efforts of the whole community; and (6) it focuses on the areas through which the capability of the community can be enhanced.

\subsection{Flood Experience}

Households carry experience of negative feelings of flood, according to 'inoculation hypothesis' (Norris and Murrell, 1988; Slovic, 1987). The fear of impending risk makes them careful in confronting and overcoming flood (Chongfu, 2014). Attentiveness is more in the person with risk experience than the one without it (Brilly and Polic, 2005). However, there is difference in risk perception even in cases with similar experience of flood (Ruin et al., 2007, Kaiser et al., 2004, Siegrist et al., 2008). Weinstein (1989) described three ways by which experience can affect risk perception (1) societal attention, at the time of flood occurrence; (2) victim-directed influence like education and social norms; and, (3) intraindividual response (cited from Howe, 2009). The approach and outlook which develop after the assessment of risk (Lazo et al., 2010) lead to adaptation (Tompkins and Adger, 2004), of protective actions (Weinstein, 1989) to resist future flooding (Raaijmakers et al., 2008).

The impetus for adaptation of measures to cope flood depends on the level of perceived risk of households (Reid et al., 2007). If risk is not a fear, there will be no effort for adaptation (Smit and Wandel, 2006). It is flood experience and risk perception, which enforce households to make livelihood sustainable (Harvatt et al., 2011) in perilous situation (Berkes, 2007). Thus, the cognitive factors play significant role in livelihood resilience (Grothmann and Reusswig, 2006). The experience and consciousness of impending risk is vital in adaptation of livelihood resilience (Grothmann and Patt, 2005) by adapting different activities to sustain and maintain livelihood (Ellis, 1998; Niehof, 2004). The diversification and adaptation of livelihood strategies to refrain flood is influenced by flood experience and risk perception (Slovic et al., 2004). According to protection motivation theory (PMT), which takes into account the threat appraisal process and coping appraisal process. Flood experience and response help households residing in flood prone areas to safeguard themselves through adaptation (Bubeck, Botzen and Aerts, 2013). The threat appraisal process is based on the apprehension of risk and its repercussions, while coping appraisal process is based on response efficacy (individual's expectancy that carrying out recommendation can remove the threat), and self-efficacy (belief in one's ability to execute the recommend courses of action successfully) to withstand, confront, and resist flooding (Rogers,1983). The protection motivation theory (PMT) has divided responses into two categories, i.e., protective responses and non-protective responses. Protective responses are applied when threat appraisal and coping appraisal are high to prevent monetary or physical damage. On the other hand, in non-protective responses, the threat appraisal is high and coping appraisal is low as was found by Milne et al. (2000) in the metaanalysis of PMT research, considering 27 studies 
involving 7694 participants. High-risk perception makes households to adapt coping responses, which may be either protective or non-protective response (Abraham et al., 1994). The model of private proactive adaptation to climate change (MPPACC) renamed threat appraisal to risk appraisal and coping appraisal to adaptation appraisal. However, adaptation appraisal, or perceived adaptive capacity has not been included in studies of risk perception after flood. The study (Grothmann and Reusswig, 2006) which reveals the relation between risk perception and adaptation processes is based on a case study. There is a lack of empirical study showing the relation between the role of risk perception and adaptation of households for livelihood resilience.

The acceptance and avoidance of risk is voluntary to households (Raaijmakers et al., 2008). The fear of being vulnerable and consciousness of risk boost households' resilience and actions to cope with flood (Grothmann and Reusswig, 2006; Ludy and Kondolf, 2012). However, studies differ about the nature of relationship between flood experience, risk perception, and mitigation method. In the study of hurricane and storm risk by Peacock et al. (2005), the experience and damage of flood led to enhancement of risk perception resulting in improved precautionary actions (Lindell and Perry, 2000) to mitigate flood risk (Mileti, 1999). The threat of flood enhances adaptation of livelihood strategies of households (Botha et al., 2011). Flood experiences amplify risk perception and consequently the behavior of recovery and adaptation. These are important components of livelihood resilience building and risk reduction (Bubeck, Botzen and Aerts, 2012) after flood. The households' flood experience and perception of risk influence their responses to control (Harvatt et al., 2011) and initiate precautionary measures to overcome flood (Harvatt et al., 2011) and make themselves resilient (Fatti and Patel, 2013).

The way households perceive flood risk and resulting damages determine households' responses to and management of flood risk (Harvatt et al., 2011). Studies reveal that the personal experience of destruction of livelihood increases the fear of flood risk perception (Plapp and Werner, 2006; Siegrist and Gutscher, 2006) and motivate households to accelerate efforts for livelihood resilience. On the other hand, there are studies which do not find any influence of risk perception on private mitigation strategies (Bubeck, Botzen and Aerts, 2012; Nyakundi, Mogere, Mwanzo and
Yitambe, 2010) or decreases risk perception after flood experience (Brilly and Polic, 2005; Botzen, Aerts and van den Bergh, 2009). Therefore, the differences in approaches of households with regard to acceptance or ignorance of risk are reflected in their livelihood resilience. Therefore, the present study looks into risk perception as a mediator between flood experience and livelihood resilience.

The experience of flood is a key component in flood risk management. It determines households' responses to flood warnings and their efforts to improve preparedness (Botzen, Aerts and van den Bergh, 2009b; Aboagye, Dari and Koomson, 2013). It always alerts households to remain prepared to meet flood challenges (Few et al., 2005), and enables them to adjust with and respond to the flooding situation to minimize flood damages (McCarthy et al., 2001). The self-protective measures based on personal experience keep households ready for future ones (Weinstein, 1989). Jackson (1981) found that experience of earthquake influence households' preventive measures.

Households use their experience in adapting and coordinating flood mitigation measures like laying sand bags in flood prone areas (Anderson, 1965), and how to participate in rescue activities (Perry and Lindell, 1978). They themselves attempt to save their lives and property (Keogh et al., 2011). Knowledge and experience provide strategic input to the affected households in their efforts to mitigate flood effects (the theory of bounded rationality), (Smith, 2001). It comes in handy to households in designing suitable measures to mitigate flood impacts (Tapsell, 2001) and also broadens their perception and responses to an event (Cutter,1993). Households develop ways to minimize damages and devise livelihood strategies in view of the nature and extent of damages, on the one hand, and make optimal use of available resources, on the other. They remain prepared to handle the dreadful effects of flooding (Cash and Moser, 2000). In course of time, it becomes their strength to withstand the unstable situation (Robyn, 2012), according to the social constructionist theory (Loseke, 1999). Households' knowledge and experience of flood find to be better equipped in dealing with flooding (Brilly and Polic, 2005; Wilson, 2012) and always keep them alert and motivated with emergency preparedness to meet flood challenges (Mileti,1999). The social constructionists explain how households through 
personal experience and interaction respond to flood (Stabllings, 1995).

\section{$\mathbf{H}_{1:}$ Risk Perception would mediate between Flood Experience and Livelihood Resilience.}

Households' experience of flood and worries to it are reflected in their preparedness level (Raaijmakers et al., 2008). Raaijmakers et al., (2008) observed that experience generates awareness, understanding along with worry, which decreased after long time. The community disaster resilience framework emphasized that more the households have resilience building capacity, less would be their worries about repercussions of flood (Raaijmakers et al., 2008) (Fig.1).

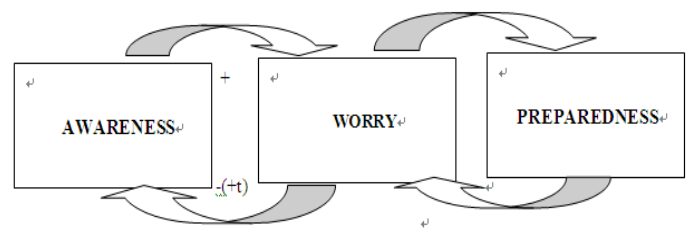

Fig. 1: Relationship between Flood characteristics (cited from Raaijmakers, 2008)

Households' repeated experience to flood enriches their understanding of the nature of flood, which is ultimately helping them in their livelihood resilience (Grothmannw and Reusswig, 2006). Furthermore, flood experience helps household in overcoming flood impact (Pagneux et al., 2011) by responding through preparedness measures which facilitate their efforts in livelihood resilience (Paton et al., 2006). Livelihood resilience measures do not only mean to protect from flood but also taking proactive measures to control flood (Longstaff, 2005). It enhances households' efforts and abilities (Folke et al., 2003) which assist them to adapt in hazardous and uncertain conditions (Lengnick-Hall and Beck, 2005). The anticipation of flood risk and the destruction it causes, trouble the households, who accordingly may remain prepared for future event, so that the impacts can be reduced, and their property and life can be saved (Howe, 2011).

There are a number of studies of impact of disaster preparedness (Lindell and Perry, 2000) on socio-demographic characteristic of the households. On the contradiction, there are studies, which show that there is no correlation between flood experiences and flood preparedness measures (Lin et al., 2008) despite being frequently affected by flood. In a nationwide survey of earthquake risk in Taiwan, Lin et al. (2008) did not find any relation between experience, risk perception, and households' preparation. In survey of flood preparedness in the Maribyrnong (Victoria) (Victoria State Emergency Service (VICSES), 2008), and in 2005 survey of flood prone properties in Maitland, NSW (New South Wales) (HunterCentral River Catchment Management Authority, 2005); shows that there is minimum or no preparedness plan to combat flood (Gissing, Keys and Opper, 2012). In another survey of landslide victims in Taiwan, support shows that disaster experience does not have any bearing on preparedness (Ho et al., 2008). While on the other hand, in the study by Slovic (2000) of hurricane reveals that flood experience stimulates flood preparedness. However, there is paucity of study, to establish that flood preparedness stimulates households' livelihood resilience after flood.

$\mathbf{H}_{2}$ : Flood experience would influence livelihood
resilience through flood preparedness.

Therefore, the first objective of the study is to assess the mediating role of risk perception, flood preparedness on flood experience, and livelihood resilience.

\subsection{Flood Education}

Education, in general, broadens households' understanding of the social and physical world around them; flood education creates awareness with regard to pros and cons of flooding in particular. Flood education is defined as 'any learning process or activity that builds households resilience to flooding' (Dufty, 2008). In a critical situation of flood and in recovery of livelihood, it comes in handy to households' rescue, improves their capabilities, and knowledge to marshalling political and economic advantages (Srinivas, 1996). In flood management, awareness creation and issuance of warning before hand play crucial role (Elliott et al., 2003). Webber and Dufty (2008) identified 'preparedness conversion', 'mitigation behavior'; 'adaptive capability', 'community competencies' and, 'post-flood learning' as an important function of disaster education. Though in the guidelines for disaster management (MariaSabo and Gavrila, 2011; UNISDR, 2009) it is suggested that disaster education plays a vital role in minimizing flood impact, but it is not included in the government's mitigation measures. Moreover, the government's awareness programs do not properly emphasize on provisioning, protection, 
and promotion of livelihood resilience. In livelihood provisioning, food and health relief are provided to households who are chronically vulnerable, whereas livelihood protection intervention includes income transfer, infrastructure repair, rehabilitation, and improvements, besides food or cash for work or other means and compensation for assets such as tools, boats and seeds. Livelihood promotion is a set of development initiatives of households to diversify their livelihood strategies; create alternative income-generating activities; provide financial services, such as loans and insurance and strengthen markets (cited from The Household Livelihood Security Concept, Retrieved from ftp://ftp.fao.org/docrep/fao/X0051t /X0051t05.pdf). In most of the studies, flood education had not been looked as an important factor in constructing livelihood resilience (Paton et al., 2006).

Paton et al. (2006) stated that resilience is a measure of how well households and societies can adapt to a changed reality and capitalize on new possibilities offered. Flood education by making forecasts, issuing early warnings, outlines recovery procedures (Heinz, 2000) which help households to resist and overcome flood impact. It further generates awareness among them with regard to adaptive measures (Botzen et al., 2009) for livelihood restoration (Berkes, 2007). However, the attitude and sensitivity of households towards risk is important in adaption of strategies to diversify income sources, and self-organize before, during and after flood. The efforts and responses of households to resist flood depend on their consciousness (Fielding et al., 2005). However, Palm (1981) found that disaster education does not guarantee 'risk avoidance behavior', but is about 'preventive measures' to protect households (Howe, 2009). Therefore, there is a need to create consciousness, and competencies among households for their livelihood resilience (Dufty, 2008). Studies show how consciousness is significant in flood mitigation measures of households (Pagneux et al., 2011; Burningham et al., 2008; Miceli et al., 2008; Weinstein, 1989) which may be enhanced through training to improve their adjustment and adaption of opportunities of income and potential precautionary measures to enable them in restoring their livelihood bases. Therefore, risk perception plays a prominent role in creating awareness and enhancing understanding about future occurrences of flood (Raaijmakers et al., 2008). Thus, the study tries to explore the mediation of risk perception between flood education and livelihood resilience.

\section{$\mathbf{H}_{3:}$ Risk perception would mediate between livelihood resilience and flood education.}

Not only risk perceptions of households motivate them towards resilience measures, but flood preparedness also facilitates them in their livelihood restoration. Furthermore, Dufty (2008) emphasized that 'Flood education can facilitate the community to build its capability (networks, leadership, and competencies) for preparedness, response, and recovery and involve the community in the planning, implementation and evaluation phases'. Households with knowledge and being aware of potential impact of hazards remain prepared with contingency plans to meet challenges arising out of flooding conditions (Bauman, 1983). The protective measures give proper direction and stimulate the process of resilience so that livelihood can be regenerated without any heavy loss (Dufty, 2008). The attentiveness of potential hazard keep household prepared with emergency plans to meet the challenges arising from flood (Bauman, 1983). Study show how disaster education increases preparedness for hurricane (Faupel et al., 1992). On the contrary, studies also show that in spite of learning through flood education, it does not stimulate households for livelihood resilience (Boura, 1998; Paton et al., 2003).

Along with flood control and mitigation, the pre-flood preparedness practices help in restructuring livelihood activities is an important concern, which needs attention. The improvement in capabilities and diversification of livelihood help households to bounce back to normal life (Walker et al., 2004) without experiencing much destruction in their day-to-day life. The awareness programs mainly focuses on mitigation and coping measures but there is dearth of study which aid in adaptation and restoration of livelihood. The needs and involvement of households in flood prone area may be given proper consideration instead of fixing the flood education process only to disseminate knowledge so that it cannot be one-way approach (O’Neill, 2004). Flood education is a most essential factor in mitigation and management (Berkes and Folke, 1998) of flood control (Berke, 1998; Burby et al., 2000) but flood preparedness enhance livelihood resilience is not elucidated (Burby, 1998; Burby et al., 2000). Hence, the study articulates flood preparedness as an intervening 
aspect between flood education and livelihood resilience.

\section{$\mathbf{H}_{4}$ : Flood experience would influence livelihood resilience through flood preparedness.}

Hence, the second objective of the study is to find out the mediating role of risk perception, and flood preparedness between flood education and livelihood resilience.

\section{Study Area and Sampling Strategy}

The study was conducted in the district of Bhagalpur, Bihar. It has an area of $2570 \mathrm{sq} \mathrm{km}$ and the rivers Ganga and Kosi traverse throughout the district. The southern part of the district falls in the Badua-Koa sub-basin of the river Ganga, and the area in north of Ganga falls under the BaghmatiKosi sub-basin. These two sub-basins constitute the Mid-Ganga basin that causes severe damage to life and property. The district is principally drained by the river Ganga, which enters the district at Sultanganj. The northern boundary of the district is marked by the river Kosi (Ghugri) heavily laden with silt and sand. Geomorphologically, the district forms a part of the Mid-Ganga foreland basin (Ministry of Water Resources, 2009). Fig.2 shows the flood inundated area of Bhagalpur district.
The study is based on the primary and secondary data, and focus group discussion. The primary data were collected by using multi-stage random sampling technique. In the first stage, the purposive sampling method was used to identify the blocks, which have remained inundated in the last 6 years during successive floods with the help of data provided by the Bihar Disaster Management Department, and in consultation with block development officers (BDOs). Based on the data obtained, out of 13 blocks, which are often affected by flood, 7 blocks (Bihpur, Ismailpur, Gopalpur, Rangra Chowk, Kharik, Narayanpur, and Naugachhia) are selected for study. Table 1 shows the number of village and size of population of the blocks. The secondary data were collected from the records of the district planning board, various Depts. of the Governments of Bihar dealing and several other documents and reports published from time to time with regards to the issue of flood in the state.

\subsection{Focus Group Discussion}

Focus group discussions were arranged in each block of the area under investigation to ascertain the views of the village people with regard to the issue of livelihood resilience of the flood affected households and other flood related issues. In the

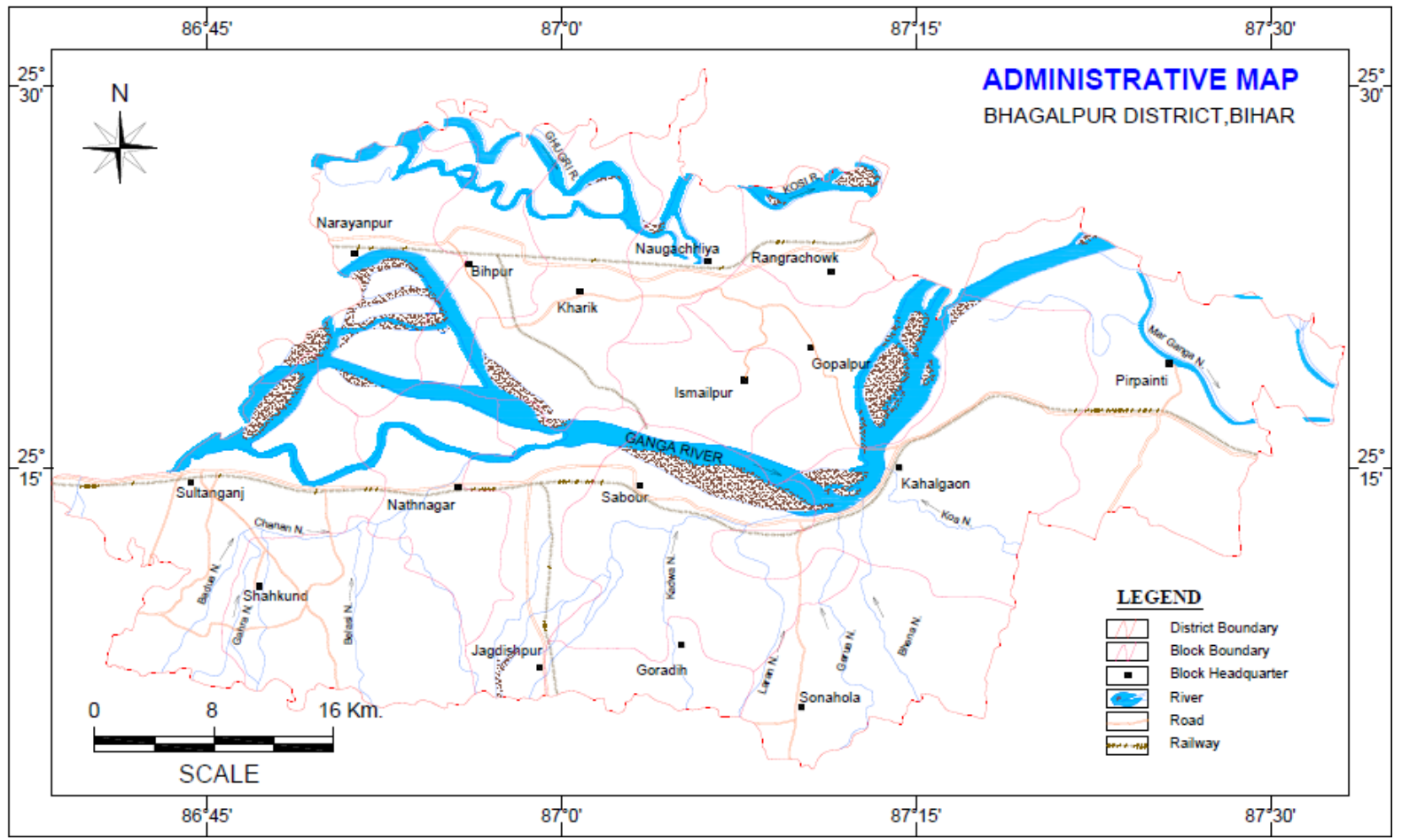

Fig. 2: Administrative Map of Bhagalpur District, Bihar (Central ground water board, Ministry of Water resources, 2009). 
Table 1: Number of Village and Size of Population of the Blocks

\begin{tabular}{|l|l|c|c|}
\hline $\begin{array}{l}\text { Sl. } \\
\text { No }\end{array}$ & Blocks & Villages & $\begin{array}{c}\text { Population } \\
\text { in the Block }\end{array}$ \\
\hline 1. & Ismailpur & 6 & 6,277 \\
\hline 2. & Gopalpur & 11 & 76,420 \\
\hline 3. & Rangra Chowk & 9 & 72,780 \\
\hline 4. & Kharik & 19 & 102,825 \\
\hline 5. & Bihpur & 22 & 97,033 \\
\hline 6. & Narayanpur & 15 & 81,971 \\
\hline 7. & Naugachia & 12 & 122,809 \\
\hline
\end{tabular}

Source: http://www.allaboutbihar.com

focus groups discussions, the issues of livelihood resilience measures, households apply to cope with flood were discussed. Groups were constituted in all the blocks consisting of randomly selected ten members in each group. In groups only those members were included whose names did not figure in the list of respondents for quantitative data collection. Before the focus group discussions were held in actual, the researcher met the village persons and explained about the purpose of discussion. They were requested to express their opinion frankly without any fear or prejudice. Initially, the village people were very reluctant and were not agreeing for discussion due to their bitter experience of the government's approach to their plight during flooding. It was a tough time for the researcher to convince. It was then that village people very hesitatingly agreed to take part in discussion. After that, the place, time, and dates were decided as suggested by village people. Before, the actual discussions, the members were requested to follow an order and express their opinion without hesitation one by one. Tea with biscuits was arranged for adult members and toffee for young children. All the members were then requested to ensure everyone's participation. Members were than frankly requested to share their experience and opinion on the issue raised. The questions raised for discussion were the following:

- What do you do to cope with flood within the household and in the farm?

- How do you manage to reconstruct your livelihood after flood, or how do you survive in the flood prone area?

With regard to the first question, members stated, "Since flood a recurring phenomenon in the area, they have become habituated to live with it." They closely watch over flood progress and remain ready to evacuate any time. They also identify places where they can keep their belongings safely when floodwater will cover the danger level. They move to safer places with their belongings, which they could carry with them. The heavy items of the household are kept on the rooftop of the dwellings, or tied with the roof. Temporary shelters are made of plastic on the roadside, railway track, national highway, and other high land areas. Food is rarely cooked and water and other essentials of life are arranged with great difficulty. The government though provides food packets and other items but it is not being made available to everyone. It is often too short of households' requirements. In order to meet food requirement in emergency conditions, they keep which are traditional fast food, items ready to eat during flood. Vegetables are grown in house premises. As floodwater stays for three to four months, households go for traditional farming. One of the members mentioned that it is because of her (Ganga river) displeasure that she brought silt and sand to our land. Ganga river is worshipped as holy mother. One of the respondents said, "We are poor people and have no savings but we work as daily wage laborer (roj kamne and khane wale log). The damage and destruction caused by flood has made our life hell. Flooding is a curse to them in their opinion. It destroys all their resources support base - resultantly many households migrate to other places in search of livelihood. The government officials in connivance with the political leaders takes away for themselves all the relief assistance government sends for distribution among flood victims. It is an open loot of the government resources, and no action is taken against erring officials and persons in spite of several complaints.

\subsection{Measures}

The following section details the measurement scales and the items (Table 2) used in measuring the constructs. In-depth interviews were conducted with key informants at three study sites. Information from the qualitative research was used for designing the structured interview schedule for household survey. The final measurement scales and design of the interview schedule on a five point Likert scale. AMOS and SPSS software was used to analyze the data.

\section{Results and Analysis}

\subsection{Preliminary Data Analysis}

The preliminary data analysis, reliability estimation, confirmatory factor analysis through 
Table 2: Measurement and Scales of Items.

\begin{tabular}{|l|c|l|l|}
\hline $\begin{array}{l}\text { Measured } \\
\text { Variable }\end{array}$ & $\begin{array}{l}\text { No. of } \\
\text { Items }\end{array}$ & \multicolumn{1}{|c|}{ Measurement Scale } & \multicolumn{1}{c|}{ Source } \\
\hline $\begin{array}{l}\text { Flood } \\
\text { Experience }\end{array}$ & 11 & $\begin{array}{l}1=\text { not exposed to flood } \\
5=\text { very severely exposed } \\
\text { to flood }\end{array}$ & $\begin{array}{l}\text { Tyler and Hoyt (2000); Norris and Murrell (1998); Susan } \\
\text { et al. (1996) }\end{array}$ \\
\hline $\begin{array}{l}\text { Flood } \\
\text { Education }\end{array}$ & 6 & $\begin{array}{l}1=\text { strongly disagree } \\
5=\text { strongly agree }\end{array}$ & Dufty (2008); Mishra and Suar (2005) \\
\hline $\begin{array}{l}\text { Livelihood } \\
\text { Resilience }\end{array}$ & 15 & $\begin{array}{l}1=\text { not at all } \\
5=\text { much more than usual }\end{array}$ & $\begin{array}{l}\text { Household Questionnaire: Survey of Living Conditions, } \\
\text { Uttar Pradesh and Bihar adapted from World Bank (1997); } \\
\text { Hahn et al. (2009); DHS (2006); WHO/RBM (2003); } \\
\text { Fernando (2003); Patnaik and Narayanan (2010); Scoones } \\
\text { (1998); Little et al. (2001) }\end{array}$ \\
\hline $\begin{array}{l}\text { Risk } \\
\text { Perception }\end{array}$ & 6 & $\begin{array}{l}\text { Slovic et al. (1980) } \\
5=\text { not at all }\end{array}$ \\
\hline $\begin{array}{l}\text { Flood } \\
\text { Preparedness }\end{array}$ & 11 & $\begin{array}{l}1=\text { mot at all } \\
5=\text { much more than usual }\end{array}$ & $\begin{array}{l}\text { Mulilis et al. (1990); Brun et al. (1997); van der Veen and } \\
\text { Logtmeijer (2005) }\end{array}$ \\
\hline
\end{tabular}

structural equation modeling was used to analyze and interpret the data. The normality of the variables was tested by skewness and kurtosis.

\subsection{Reliability of the Measurement Scales}

In accordance with the Chronbach alpha test, all the constructs except flood preparedness obtained an acceptable of a coefficient alpha above .70 (Table 3 ) indicating that the measurement scales were reliable and appropriate for further data analysis.

\subsection{Correlations between Variables}

During the preliminary analysis of data, the mean and standard deviation were obtained for each variable. The correlation gave preliminary support for the hypotheses of the study (Table 4). Flood experience was negatively correlated and insignificant to livelihood resilience $(\mathrm{r}=-.075$, $\mathrm{p}>.01)$. Flood education was also negatively correlated to livelihood resilience but significant $(\mathrm{r}=-.272, \mathrm{p}<.01)$. However, risk perception was positively correlated to livelihood resilience and significant $(\mathrm{r}=.172, \mathrm{p}<.01)$. The correlation between flood preparedness and livelihood resilience was significant but negative $(\mathrm{r}=-.413$, $\mathrm{p}<.01)$. The study also explored the relation between flood experience and risk perception $(\mathrm{r}=.585, \mathrm{p}>.01)$ but the correlation between flood

Table 3: Summary of Measurement Reliability

\begin{tabular}{|c|c|c|c|c|}
\hline & Measured Variables & No. of Items & Items Remained & Cronbach Alpha \\
\hline 1. & Flood Experience & 11 & 11 & .87 \\
\hline 2. & Flood Education & 4 & 4 & .71 \\
\hline 3. & Livelihood Resilience & 15 & 15 & .78 \\
\hline 4. & Risk Perception & 6 & 6 & .80 \\
\hline 5. & Flood Preparedness & 11 & 11 & .69 \\
\hline
\end{tabular}

Table 4: Correlation between the Variables

\begin{tabular}{|l|c|c|c|c|c|c|c|}
\hline & M & SD & FLEX & FLED & LVRS & RSPR & FLPP \\
\hline FLEX & 45.84 & 11.50 & 1 & & & & \\
\hline FLED & 6.77 & 4.38 & $.306^{* *}$ & 1 & & & \\
\hline LVRS & 50.21 & .550 & -.075 & $-.413^{* *}$ & 1 & & \\
\hline RSPR & 17.90 & -623 & $.585^{* *}$ & $.207^{* *}$ & -.011 & 1 & \\
\hline FLPP & 17.76 & .147 & .084 & $.526^{* *}$ & $-.397^{* *}$ & 0.17 & 1 \\
\hline
\end{tabular}


experience and flood preparedness $(\mathrm{r}=.084$, $\mathrm{p}<.05)$ was also significant. The correlation linking flood education and risk perception $(\mathrm{r}=.207, \mathrm{p}<.01)$ and flood preparedness $(\mathrm{r}=.526, \mathrm{p}<.01)$ was also significant.

\section{Factor analysis}

\subsection{Exploratory Factor Analysis}

Factor analysis is an interdependent technique, which aims to determine the underlying structure among variables (Hair et al., 1998). As livelihood resilience scale was prepared by the researcher through focus group discussion and interview with informants, therefore, in order to ascertain how and up to what extent the items of the scale were linked to the construct in a different context, exploratory factor analysis (EFA) method was applied on the sample $(\mathrm{N}=472)$. The sample was subjected to principal components analysis (PCA). Prior to performing PCA the suitability of data for factor analysis was assessed. Inspection of the correlation matrix revealed the presence of correlation coefficients of .3 and above. The Kaiser-MeyerOklin value of the variable (.628) was exceeding the recommended value of .6 (Kaiser, 1970) and the Barlett's Test of Sphericity (Bartlett,1954) reached statistical significance $(\mathrm{p}<.01)$, supporting the factorability of the correlation matrix (Hair et al., 1998).

In EFA, first the unrotated factor matrix was computed, containing the factor loading for variable on factor. Factor loading is the correlation of variables and the factor. The higher loading makes the variable representative of the factor. The factor-loading matrix was examined and significant loading was identified. In the sample size of 472 , factor loading of .35 and higher was considered significant for interpretive purpose. Variables having communalities of greater than .50 were retained in the analysis. The unrotated factor solution did not provide adequate information of variables under examination. In the unrotated factor loading variables, having cross loading and those with low significance was identified. Catell (1966) scree test was also used to identify the optimum number of factors that can be extracted. This was further confirmed by the results of parallel analysis, which showed components with eigen values exceeding the corresponding criterion values for a randomly generated data matrix of the same size.

To achieve simpler and theoretically more meaningful factor solution, orthogonal approach with varimax factor rotation method was used, which attempted to minimize the number of variables that had a high loading on factor. The rotated solution revealed the presence of simple structure (Thurstone, 1947) with factors showing a number of strong loadings. The loadings were improved for almost every item. The factor loading of the items ranges between .543 to .657 , the eigen value was 3.976 and variance was 25.6. For further analysis of the constructs, latent variable structural equation modeling method was used.

\subsection{Latent Variable Structural Equation Modeling (LVSEM)}

Latent variable structural equation modeling (LVSEM) tests the sequential relationship between a series of independent and dependent variables. It assists in specifying measurement model as well as structural models

There are two components of SEM, measurement model and structural model. The measurement model was evaluated by using Confirmatory Factor Analysis (CFA). The measurement model specifies the posited relationships of the observed indicators to the latent construct. Therefore, before testing the overall measurement model, each construct in the model was evaluated and analyzed separately by respecification of the model. The model respecification procedure was used to identify the source of misfit and to generate a model that achieves better fit to the data. The measurement model was modified by examining the standardized residuals, modification indices, and the standardized loading estimates (Hair et al., 2006). Each of the measures was examined together with the model fit indices to ascertain if respecification was needed. The model fit was examined using multiple indices such as $\chi^{2}$ and the $\chi^{2} / \mathrm{df}$, GFI, CFI, TLI, RMSEA. After the modification of the fit indices, the final CFA model was improved. The revised measurement model fit the data well. Further, when each construct had shown an acceptable fit to the model, then all constructs were evaluated together (Table 5).

Hypothesis $\left(\mathbf{H}_{\mathbf{1}}\right)$ : Risk Perception would mediate between Flood Experience and Livelihood Resilience.

The present study also examined (H1) the relationship between flood experience and livelihood resilience mediated by risk perception. At first the direct relationship was determined (Table 6), i.e., (a) regression was run to predict 
Table 5: Summary of CFA Result and Model fit Indices ( $\mathrm{N}=472)$

\begin{tabular}{|l|l|l|}
\hline \multicolumn{1}{|c|}{ Construct } & CFA Items & Reliability \\
\hline 4. Flood Experience & 6 & .82 \\
\hline$\chi^{2}=42.3 ; \chi^{2} / \mathrm{df}=3.25 ; \mathrm{p}=.000 ; \mathrm{RMSEA}=.06 ; \mathrm{GFI}=.96 ; \mathrm{TLI}=.96 ; \mathrm{CFI}=.98$ & 3 & .69 \\
\hline 5. Flood Education & 3 & \\
\hline$\chi^{2}=48.8 ; \chi^{2} / \mathrm{df}=2.9 ; \mathrm{P}=.000 ; \mathrm{RMSEA}=.00 ; \mathrm{GFI}=.99 ; \mathrm{TLI}=1.00 ; \mathrm{CFI}=1.00$ & \\
\hline 6. Livelihood Resilience & 6 & .70 \\
\hline$\chi^{2}=18.6 ; \chi^{2} / \mathrm{df}=2.3 ; \mathrm{p}=.000 ; \mathrm{RMSEA}=.05 ; \mathrm{GFI}=.98 ; \mathrm{TLI}=.97 ; \mathrm{CFI}=.98$ & .78 \\
\hline 7. Risk Perception & 5 \\
\hline$\chi^{2}=17.14 ; \chi^{2} / \mathrm{df}=3.4 ; \mathrm{p}=.004 ; \mathrm{RMSEA}=.07 ; \mathrm{GFI}=.98 ; \mathrm{TLI}=.98 ; \mathrm{CFI}=.99$ & .70 \\
\hline 8. Flood Preparedness & 5 \\
\hline$\chi^{2}=21.77 ; \chi^{2} / \mathrm{df}=2.7 ; \mathrm{p}=.000 ; \mathrm{RMSEA}=.06 ; \mathrm{GFI}=.98 ; \mathrm{TLI}=.90 ; \mathrm{CFI}=.94$ \\
\hline
\end{tabular}

Table 6: Hypothesis Testing of Risk Perception as Mediator between Flood Experience and Livelihood Resilience

\begin{tabular}{|c|c|c|c|c|c|}
\hline Hypothesized path & Direction & Beta estimate & C.R/ t value & SE & Decision \\
\hline LVRS $\leftarrow$ FLEX & + & $.037^{*}$ & 3.28 & .037 & Supported \\
\hline FLPP $\leftarrow$ FLEX & + & $.158^{*}$ & 4.43 & .058 & Supported \\
\hline LVRS $\leftarrow$ FLPP & + & $.164^{*}$ & 2.74 & .060 & Supported \\
\hline
\end{tabular}

Note: $\beta=$ regression weight; ${ }^{*} p<.05,{ }^{* *} p<.01$ (2-tailed)

livelihood resilience from flood experience $(\beta=.37, \mathrm{p}<.01$, c.r. $=3.2)$ was significant and supported; (b) the regression coefficient for the prediction of risk perception from flood experience was negative and statistically insignificant $(\beta 1=-.90, p>.05$, c.r $=-1.79)$; (c) next, regression was performed to predict the effect of risk perception on livelihood resilience which was significant and positive $(\beta 3=.174, \mathrm{p}<.01$, c.r. = 4.0); and, (d) with risk perception in equation, the regression coefficient was not smaller than the $\beta 1(\beta 4=.082, p>.05$, c.r $=1.73)$, further the $\beta 1$ was not significant; risk perception had no mediation in the relationship between flood experience and livelihood resilience. Table 7 reveals the indirect effect was not supporting the mediation. Therefore, H1 was refuted.

Hypothesis $\left.\mathbf{( H}_{\mathbf{2}}\right)$ : Flood experience would influence livelihood resilience through flood preparedness.

Next, the hypothesis $\left(\mathrm{H}_{2}\right)$ of the study is when mediator flood preparedness was taken into account the relationship between flood experience and livelihood resilience would be more powerful. Before considering the position of flood preparedness as mediator in the analysis, at first the bivariate association between flood experience and livelihood resilience was established (Table 8) (a) Flood experience significantly account for variations in livelihood resilience $(\beta=.37, \mathrm{p}<.01$ ,c.r. $=3.2$ ); (b) the relationship between flood experience and flood preparedness was significant $\left(\beta_{2}=.158, \mathrm{p}<.01\right.$, c.r. $\left.=4.4\right)$; $(\mathrm{c})$ flood preparedness significantly account for variation in livelihood resilience $\left(\beta_{3}=.164, p \quad<.01, \quad\right.$ c.r $\left.=2.7\right)$; and,(d) with flood preparedness in equation, the regression coefficient of flood experience to livelihood resilience was smaller than the $\beta_{1}\left(\beta_{4}=.037, \mathrm{p}<\right.$ .05 , c.r. $=2.3)$, further the $\beta_{1}$ was still significant, flood preparedness had a partial mediating effect on the relationship between flood experience and livelihood resilience. Table 9 shows the direct, indirect, and total effect of mediation. Therefore, $\mathrm{H}_{2}$ was supported. Figure 3 shows the Hypothesis $\mathrm{H}_{1}$ and $\mathrm{H}_{2}$.

Table 7: Direct, Indirect, and Total Effects of Risk Perception as Mediator between Flood Experience and Livelihood Resilience

\begin{tabular}{|c|c|c|c|c|c|c|}
\hline \multirow{2}{*}{ Variable } & \multicolumn{5}{|c|}{ Variable } \\
\cline { 2 - 7 } & Direct & Indirect & Total & Direct & Indirect & Total \\
\hline FLEX & $-.90^{* *}$ & .00 & $-.90^{* *}$ & $.37^{* *}$ & .82 & $.119^{* *}$ \\
\hline RSPR & .00 & .00 & .00 & .17 & .00 & -.09 \\
\hline
\end{tabular}

Note: path estimates were reported; ${ }^{*} \mathrm{p}<.05,{ }^{* *} \mathrm{p}<.01$ (two-tailed) 
Table 8: Hypothesis Testing of Flood Preparedness as Mediator between Flood Experience and Livelihood Resilience

\begin{tabular}{|l|c|c|c|c|c|}
\hline Hypothesized path & Direction & Beta estimate & C.R/ t value & SE & Decision \\
\hline LVRS $\leftarrow$ FLEX & + & $.037^{*}$ & 3.28 & .037 & Supported \\
FLPP $\leftarrow$ FLEX & + & $.158^{*}$ & 4.43 & .058 & Supported \\
LVRS $\leftarrow$ FLPP & + & $.164^{*}$ & 2.74 & .060 & Supported \\
\hline
\end{tabular}

Table 9: Direct, Indirect, and Total Effects Flood Preparedness as Mediator between Flood Experience and Livelihood Resilience

\begin{tabular}{|c|l|c|c|c|c|c|}
\hline \multirow{2}{*}{ Variable } & \multicolumn{5}{|c|}{ VLPP } & \multicolumn{3}{c|}{ LVRS } \\
\cline { 2 - 7 } & Direct & Indirect & Total & Direct & Indirect & Total \\
\hline FLEX & $.37^{* *}$ & .00 & $.37^{* *}$ & $.37^{* *}$ & $.37^{* *}$ & $.74^{* *}$ \\
\hline FLPP & .00 & .00 & .00 & $.16^{* *}$ & .00 & $.16^{* *}$ \\
\hline
\end{tabular}

Note: path estimates were reported; ${ }^{*} \mathrm{p}<.05,{ }^{* *} \mathrm{p}<.01$ (two-tailed)

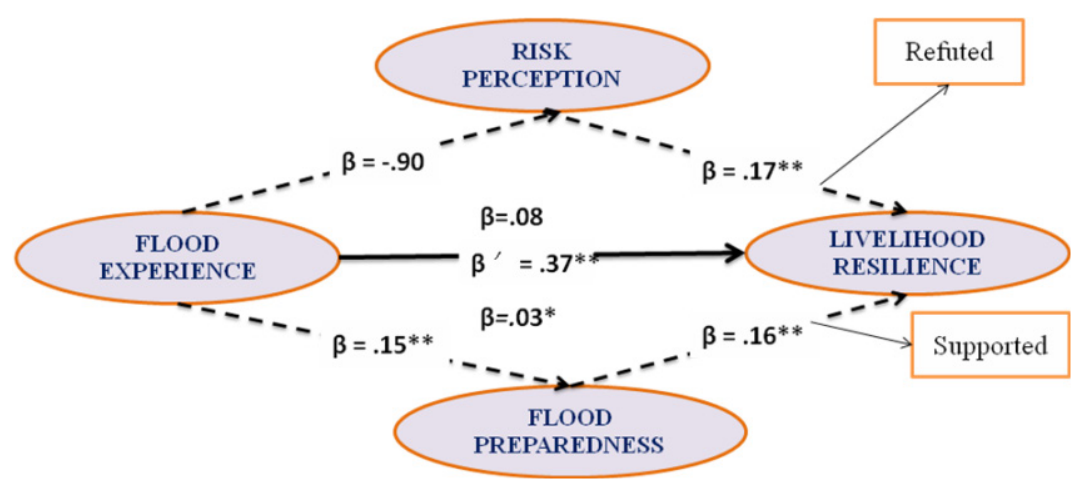

Note. Dotted lines show indirect effects $* * p<.01, * \mathrm{p}<.05$

Fig 3: Risk perception and Flood preparedness as a mediator between Flood experience and Livelihood Resilience

Hypothesis $\left(\mathbf{H}_{3}\right)$ : Risk perception would mediate between livelihood resilience and flood education.

The study also looked that $\left(\mathrm{H}_{3}\right)$ risk perception would mediate between livelihood resilience and flood education. Table 10 shows (a) flood education was significantly accounted for variations in livelihood resilience $\left(\beta_{1}=.224, \mathrm{p}\right.$ $<.01$, c.r. $=2.3$ ); (b) the relationship between flood education and risk perception was significant $\left(\beta_{2}\right.$ $=.122, \mathrm{p}<.05$, c.r. $=3.4$ ); (c) risk perception was significantly accounted for variation in livelihood resilience $\left(\beta_{3}=.174, \mathrm{p}<.01\right.$, c.r. $\left.=4.0\right)$; and, $(\mathrm{d})$ with risk perception in equation, the regression coefficient was significant but negative $\beta_{2}\left(\beta_{3}=\right.$ $.296, \mathrm{p}<.05$, c.r. $=-3.1)$. Hence, there was no mediation of risk perception between flood education and livelihood resilience. Table 11 shows that the direct effect with mediator was negative. Therefore, $\mathrm{H}_{3}$ was refuted.

Hypothesis $\left(\mathbf{H}_{\mathbf{4}}\right)$ : Flood Education would influence livelihood resilience through flood preparedness.

The study also explored the relationship (H4)

Table 10: Hypothesis Testing of Risk Perception as Mediator between Flood Education and Livelihood Resilience

\begin{tabular}{|c|c|c|c|c|c|}
\hline Hypothesized path & Direction & Beta estimate & C.R/ t value & SE & Decision \\
\hline LVRS $\leftarrow$ FLED & + & $.224^{* *}$ & 2.35 & .095 & Supported \\
RSPR $\leftarrow$ FLED & + & $.122^{*}$ & 3.45 & .042 & Refuted \\
LVRS $\leftarrow$ RSPR & + & $.174^{* *}$ & 4.08 & .043 & Supported \\
\hline
\end{tabular}

Note: $\beta=$ regression weight; ${ }^{*} \mathrm{p}<.05,{ }^{* *} \mathrm{p}<.01$ (2-tailed) 
Table 11: Direct, Indirect, and Total Effects Risk Perception as Mediator between Flood Education and Livelihood Resilience

\begin{tabular}{|c|c|c|c|c|c|c|}
\hline & \multicolumn{5}{|c|}{ Variable } \\
\hline \multirow{2}{*}{ Variable } & \multicolumn{3}{|c|}{ RSPR } & \multicolumn{3}{c|}{ LVRS } \\
\cline { 2 - 7 } & Direct & Indirect & Total & Direct & Indirect & Total \\
\hline FLED & $.22^{* *}$ & .00 & $.22^{* *}$ & $.22^{* *}$ & $.29^{* *}$ & $.51^{* *}$ \\
\hline RSPR & .00 & .00 & .00 & $.17^{* *}$ & .00 & $.17^{* *}$ \\
\hline
\end{tabular}

Note: path estimates were reported; ${ }^{*} \mathrm{p}<.05,{ }^{* *} \mathrm{p}<.01$ (two-tailed)

between flood education and livelihood resilience. Table 12 reveals (a) flood education significantly accounted for variations in livelihood resilience $(\beta 1$ $=.224, \quad \mathrm{p}<.01, \quad$ c.r. $=2.3$ ); (b) the relationship between flood education and flood preparedness was significant $(\beta 2=.472, \mathrm{p}<.05, \quad$ c.r. $=4.02)$; (c) flood preparedness was significantly accounted for variation in livelihood resilience $(\beta 3=.178, \mathrm{p}$ $<.05$, c.r. $=2.8$ ) and, (d) with risk perception in equation, the regression coefficient between flood education and livelihood resilience was smaller than the $\beta 1(\beta 4=.164, \mathrm{p}<.01$, c.r. $=2.7)$; but the $\beta 4$ was still significant, flood preparedness has a partial mediating effect on the relationship between flood education and livelihood resilience. Table 13 shows the direct, indirect and total effect of mediation analysis, which was significant and supported. Therefore, H4 was supported.

The fit measures of the direct and indirect path (including mediators) model indicate that chi square of all the models were highly significant $(\mathrm{p}<.001)$. As chi-square was sensitive to sample size, so chi-square for degree of freedom $\left(\chi^{2} / \mathrm{df}\right)$ was estimated. The result shows that the relative chi-square was not below the required limit of 3
(Kline, 1998). GFI, CFI, NFI was close to .90 which reveals the good fit of the model. The parsimonious (PGFI, PCFI, PNFI) measures were acceptable in both the models. However, it was slightly low in the direct model because the mediation was absent in that model (Table 14). RMSEA show the approximation of the observed model to the true model, which was acceptable in this model. However, the indirect model was better than the direct model because it included all possible paths.

Therefore, the result of the hypothesized structural model reveals that the initial model did not fit the data well, and so, it was not acceptable $\left(\chi^{2}=380.6, \chi^{2} / \mathrm{df}=2.45, \mathrm{p}=.01\right.$, GFI $=.90 ;$ $\mathrm{TLI}=.91$, CFI $=.92$, RMSEA $=.06$ ). The results indicate that risk perception does not mediate between livelihood resilience and flood experience and flood education. The two hypothesized paths do not show any significant relationship between exogenous and endogenous variable. Therefore, these hypotheses paths were removed because the construct does not have any significant affect on livelihood resilience (Fig. 3) Revised Model with Standardized and Unstandardized Path

Table 12: Hypothesis Testing of Flood education would influence livelihood resilience through flood preparedness.

\begin{tabular}{|l|c|c|c|c|c|}
\hline Hypothesized path & Direction & Beta estimate & C.R/ t value & SE & Decision \\
\hline LVRS $\leftarrow$ FLED & + & $.224^{* *}$ & 2.35 & .095 & Supported \\
FLPP $\leftarrow$ FLED & + & $.472^{*}$ & 4.02 & .117 & Supported \\
LVRS $\leftarrow$ FLPP & + & $.178^{*}$ & 2.88 & .178 & Supported \\
\hline
\end{tabular}

Note: $\beta=$ regression weight; ${ }^{*} \mathrm{p}<.05,{ }^{* *} \mathrm{p}<.01$ (2-tailed)

Table13: Direct, Indirect, and Total Effects Flood Preparedness as Mediator between Flood Education and Livelihood Resilience

\begin{tabular}{|c|c|c|c|c|c|c|}
\hline & \multicolumn{5}{|c|}{ Variable } \\
\hline Variable & \multicolumn{3}{|c|}{ FLPP } & \multicolumn{3}{c|}{ LVRS } \\
\cline { 2 - 7 } & Direct & Indirect & Total & Direct & Indirect & Total \\
\hline FLED & $.22^{*}$ & .00 & .15 & $.22^{* *}$ & $.16^{* *}$ & $.48^{* *}$ \\
\hline FLPP & .00 & .00 & .00 & $.17^{*}$ & .00 & $.17^{*}$ \\
\hline
\end{tabular}

Note: path estimates were reported; ${ }^{*} \mathrm{p}<.05,{ }^{*} \mathrm{p}<.01$ (two-tailed)

Table 14: Fit Measures of Two Models Dealing with Mediation

\begin{tabular}{|c|c|c|c|c|c|c|c|c|c|}
\hline & $\boldsymbol{\chi} \mathbf{2} / \mathbf{d f}$ & $\mathbf{p}$ & GFI & TLI & CFI & PGFI & PCFI & PNFI & RMSEA \\
\hline Direct model & 2.10 & .001 & .91 & .91 & .92 & .60 & .68 & .66 & .05 \\
\hline Indirect model & 2.45 & .001 & .90 & .91 & .92 & .62 & .69 & .67 & .06 \\
\hline
\end{tabular}


Coefficient). Consequently, a more parsimonious model (Table 15) was made after deleting the nonsignificant path from the initial model $\left(\chi^{2}=326.8\right.$, $\chi^{2} / \mathrm{df}=2.04, \mathrm{p}=.00, \mathrm{GFI}=.94 ; \mathrm{TLI}=.96, \mathrm{CFI}=.98$, RMSEA $=.06)$. Figure 4 shows the Hypothesis $\mathrm{H}_{3}$ and $\mathrm{H}_{4}$. basis of their previous flood experience which saves them from much of their likely losses. Flood experience is further found to provide stability and enhances households' capability to skillfully and effectively handle flood challenges (Fig 5 and Fig. $6)$.

Table 15: Goodness of Fit Results for Structural Model

\begin{tabular}{|c|c|c|c|c|c|c|c|}
\hline Measurement Model & \multicolumn{7}{|c|}{ Goodness-of-fit Indices } \\
\cline { 2 - 8 } & $\boldsymbol{\chi}^{\mathbf{2}}$ & $\boldsymbol{\chi}^{\mathbf{2} / \mathbf{d f}}$ & $\mathbf{p}$ & GFI & TLI & CFI & RMSEA \\
\hline Initial Model & 380.6 & 2.45 & .001 & .90 & .91 & .92 & .06 \\
\hline Final Model & 326.8 & 2.04 & .000 & .94 & .96 & .98 & .07 \\
\hline
\end{tabular}

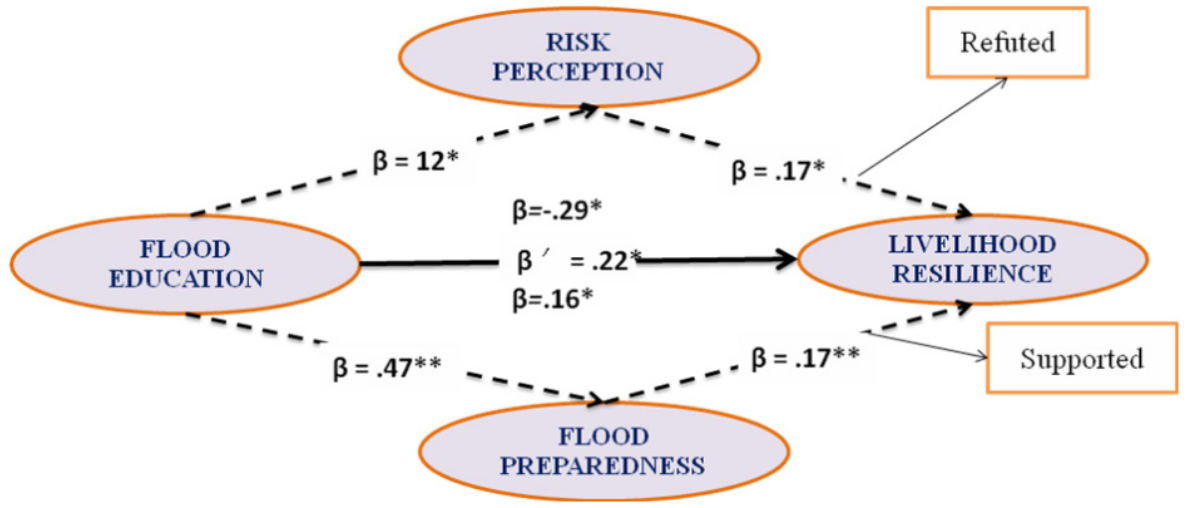

Note. Dotted lines show indirect effects ${ }^{* *} \mathrm{p}<.01,{ }^{*} \mathrm{p}<.05$

Fig 4: Risk perception and Flood preparedness as a mediator between Flood education and Livelihood Resilience

\section{Discussions}

Objective1: To assess the mediating role of risk perception, flood preparedness on flood experience, and livelihood resilience

Risk perception is not found to mediate between flood experience and livelihood resilience as the findings of the study reveal. Although, flood experience plays significant role in both flood protective behavior and flood risk perception of households, their perceived flood probabilities and perceived flood consequences do not intervene in livelihood resilience. This is consistent with the heuristic theory, which emphasizes that households do not unreasonably worry about flood impact because of their flood experience (Grothmann and Reusswig, 2006). Rather, learning from repeated exposure to flood comes in handy to households in their efforts to skillfully arrange livelihood, as it provides them added advantage when it is most needed. The learning from flood experience enables households to resist, recover, and bounce back to normal livelihood after flood. They adjust and learn to live in hazardous condition on the

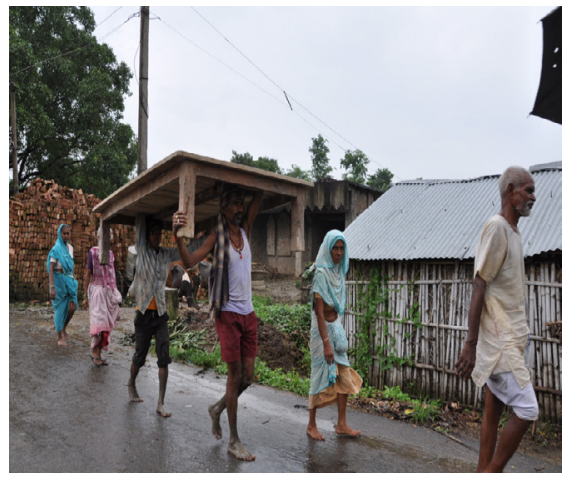

Fig. 5: Households Shifting their Belonging to a Safer Place

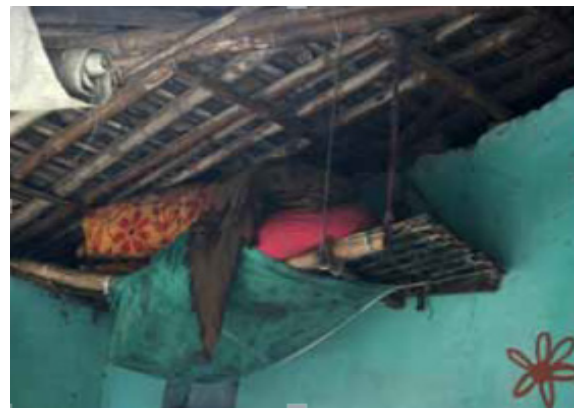

Fig. 6: Households Tie their Belongings to the Rooftop of the House 
The study is consistent with the previous literature (Bubeck, Botzen and Aerts, 2012), which found weak relationship between flood risk perceptions and mitigation measures. Households' views and perceptions about flood changes in course of time because of their repeated flood experience. As a result, they no more remain fearful of flood impacts. Their flood experience and capabilities instill further confidence in them with regard to livelihood resilience, diversification of livelihood, and income generating activities. The protection motivation theory (threat coping and threat appraisal behavior) does not hold relevance and is not imperative in livelihood resilience. The study is contrary to the study by Wachinger and Renn (2010) which found that risk perceptions influence vulnerability of the households. The study also differs with the study of Bradford et al. (2012) which proposed to develop a model of social resilience based on risk perception. However, the study confirms the assumption that risk perception largely depends on recency (Hertwig et al., 2004), frequency, and intensity of households' flood experience, but does not play role in adaptation of resilience measures.

Flood preparedness partially mediates between flood experience and livelihood resilience. The study is in contrast to the findings of the study which had found high level of emergency preparedness (Lindell and Prater, 2000), but is consistent with the study which found low and minimal preparedness (Jackson, 1981; Turner et al., 1986; Miceli et al., 2008). The study is further consistent with the study of residents in a floodprone area of Italy, which showed low level of individual-level domestic protection (De Marchi et al., 2007). Hung-Chih (2009) found a similar pattern among Taiwanese participants. Flood experience is also found to stimulate households in flood preparedness based on their understanding and familiarity with flood devastation as was found in previous studies (Basolo et al., 2009; Harvatt, Petts and Chilvers, 2010; Kirschenbaum, 2002). The result is consistent with the study of Nyakundi, Mogere, Mwanzo, and Yitambe (2010) which concluded that households' indigenous knowledge play crucial role in livelihood resilience. The resilience measures of flood control are a byproduct, or an outcome of households' direct experience of flooding and reactive mechanism to reinstate livelihood to its normal condition. Households do not evacuate or shift their belongings and livestock to safer places unless all options have not been ruled out, and households do not find themselves placed in much deep water.

Absence of boat, dinghy and other means of transportation complicate the process of households' evacuation. As a result, household follow their own ways and shift their belongings to the rooftop of the house. Dwellings of households in active flood zones are generally built on silt or elevated ground.

Objective 2: To assess the mediating role of risk perception, and flood preparedness between flood education and livelihood resilience.

The results of the study do not find mediation by risk perception between flood education and livelihood resilience as because households, in course of time, adjust with flood, live with uncertainty, and accordingly adapt resilience measures. Though there is no formal flood education programs in the study areas, households always learn from the experience of the senior persons of the community about the pros and cons of flood, and what measures may be more effective in different flooding situations. This facilitates households in making better use of the available resources to recreate livelihood. This, possibly, may be for the reason that households are neither warned, nor informed beforehand about the probable occurrences of flood and its impact on their livelihood. Besides, the government's awareness programs are often superficial and perfunctory, do not lay focus on households' attitudinal change. It does neither focus on which adaptive measures should they follow, nor which new opportunities are available to them to earn their livelihood. It only focuses on preventive measures, which though provide temporary relief to households, but does not offer any effective or lasting solution to livelihood resilience of households to reduce vulnerability. The government sponsored flood mitigation programs do not focus further on livelihood promotion.

The result of the study shows that flood preparedness mediates between flood education and livelihood resilience. Though, there is no formal flood education in the blocks of the study area, households informally learn from the experience of elders and senior members of the community about what steps should be taken in what kind of flood situation, how to mobilize resources, what measures should be adapted to protect life and property of households effectively, 
what preparatory measures should be taken to meet flood challenges, and how to approach political leadership and other external agencies to support livelihood resilience of the affected households etc. All potential problems are discussed in informal village gatherings and village chitchat sessions at length along with their possible solutions to safeguard the interests of the households in the flooding situations. In fact, households realize the significant role of elders and senior members of the community in creating awareness, dissemination of information, and flood preparatory mechanism more than what may be achieved through formal system of education (Fig. 7).

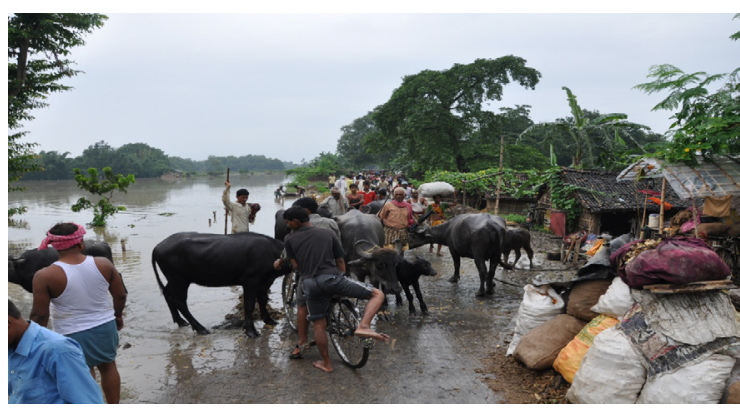

Fig. 7: Households take their livestocks to safer place(s)

However, households do acknowledge the importance of flood education with regard to various aspects of flooding. i.e., knowledge about potential impact of flooding, training to effectively handle flood situation, viability of various strategies to meet flood challenges and how to make preparation, and how to make optimal use of available resources in the given situation of flooding etc. In the opinion of majority of the households, though education about flood does exist informally, formal flood education may further add, supplement, provide or train 'flood folks" ${ }^{1}$ about how to behave them in a flooding situation, and how to act effectively to meet flood challenges. In the community, threadbare discussions take place with regard to pros and cons of various strategies of livelihood resilience and various strategic measures the community should initiate to safeguard their interest and contain flood fury. Households' live with the flood 'as a way of life'.

Resources are pulled, specific steps of action are chalked out, round the clock monitoring of floodwater is arranged, responsibilities are

$1 \mathrm{It}$ refers to a group of households who are affected by flood. distributed and all households are asked to standby if situations so warrant. The community is found to remain alert to collectively act to meet any flood eventuality. Throughout the entire flooding period, the community remains together and jointly initiates actions to support each other at the time of flooding. Loud speakers are used to update households, and petromax and other lighting arrangements are made to keep close watch over flood development.

Households flood preparedness includes storage of relief materials, storage of seeds, monitoring of floodwater, and exchange of information about safe places of shelter. Flood preparedness may further be improved and flood impacts be lessened by making arrangements for formal flood education, by organizing awareness programs, and by issuing early warning to households to remain prepared to meet any flood eventualities. The study envisages the necessity for accurate flood education program to create awareness in households in respect to flood and its accompanying problems as it may install confidence and create hope in households in the situation of despair (Berke, 1998; Burby et al., 2000; Botzen, 2009).

In the opinion of households, since the government relief assistance always comes late it may be taken care of by arranging a camp office at the site of flooding. The camp office may be interested with the responsibility to maintain liaison with the flood headquarters of the government to continuously update the government about the flood progress. A roster of households may be maintained closely monitor and watch the flood movement for onward transmission to the flood headquarters.

\section{Conclusions}

Flood experience of households and their knowledge work as strategic inputs in their livelihood resilience. Flood experience is acquired from their frequent exposure is far more the most effective and powerful weapon, which households use advantageously to fight against flood vagaries. It is used as a strategic resource input by them in their livelihood resilience. It is a process of continuous learning, which creates confidence in households and enables them to adapt measures to meet any flood eventuality. As a result, they do not perceive flood as a threat because of their experience and knowledge and their confidence in finding ways to overcome it. Households adapt the strategy of 'watch and act' and accordingly remain 
prepared with contingency plans to overcome flood impacts.

Although, flood education is not found to exist formally, younger persons informally learn from the experience of senior persons about the preventive measures to be adapted and likely to be effective in coping with flood. Wide discussion takes place among the households and in the community with regard to proactive measures when flood is visualized and considered inevitable.

Livelihood resilience depends on the ingenuity of the households, the support they receive from the community and the government, and how optimally do they use their flood experience and knowledge. In the flooding situation, the community acts together as a cohesive unit, for all being risked to the same problem. The long experience of flood enables affected households' learning and adaptation of suitable ways and means to livelihood resilience, which may further help policy makers in devising effective strategy. Therefore, there is a need to take benefit of the strategic value of people's indigenous knowledge and flood experience in livelihood resilience, as it does not depend only on distribution of relief materials, but more so depends on people's access to resources and their attitude and aspirations for livelihood resilience. The government focuses on preparedness activities but does not promote livelihood diversification strategy, which may help households in generating income and different livelihood activities. Moreover, lack of formal flood education programs does not pose any problem in households' awareness as it takes place in different informal meetings of the households. In order to meet flood challenges, involvement of all the stakeholders need to be duly considered at all levels of flood operations. People's experience and knowledge to flood which come in handy and guide them at each step in their efforts to reestablish livelihood may be advantageously utilized in strategic intervention by the government. It helps households in their strategies, according to situational requirement.

\section{Limitations}

The study though shows risk perception as mediator, but risk perception changes over time and cognitive emotions may enhance or lessen after certain time and thus, may influence livelihood resilience. This may be taken care-off by making pre and post studies, but this could not be done in this present study. An effective model by involving different stakeholders and by incorporating local issues including households' strategies may be prepared for different phases of livelihood resilience.

\section{Acknowledgement}

We are very grateful to IIT Kharagpur for providing fund to carry out the research.

\section{References}

S. C. S. Abraham, P. Sheeran, D. Abrams and R. Spears, Exploring teenagers' adaptive and mal adaptive thinking in relation to the threat of HIV infection, Psychology and Health 9 (1994) 253-272.

D. Aboagye, T. Dari and J. Koomson, Risk perception and disaster management in the savannah region of Ghana, International Journal of Humanities and Social Sciences 3(3) (2013) 157-172.

W. A. Anderson, Some Observations on a Disaster Subculture: Organizational Response of Cincinnati Ohio to the 1964 Flood. (Note BC. Columbus, Ohio: The Disaster Research Center, The Ohio State University) 1965.

D. Bauman, Determination of the Cost Effectiveness of Flood Hazard Information, Papers and proceedings of the Applied Geography Conference 6 (1983) 292.

M. S. Bartlett, A note on the multiplying factors for various chi square approximations, Journal of the Royal Statistical Society 16 (1954) 296-298.

V. Basolo, L. J. Steinberg, R. J. Burby, J. Levine, A. M. Cruz and C. Huang, The effects of confidence in government and information on perceived and actual preparedness for disasters, Environment and Behavior 41 (2009) 338-364. http://dx.doi.org/ $10.1177 / 0013916508317222$.

F. Berkes, Understanding uncertainty and reducing vulnerability: Lessons from resilience thinking, Natural Hazards 41(2) (2007) 283-95.

F. Berkes and C. Folke, Linking social and ecological systems: management practices and social mechanisms for building resilience. (Cambridge University Press, Cambridge, UK) 1998.

D. Botha, D. Van Niekerk, G. Wentink, T. Tshona, Y. Maartens, K. Forbes, E. Annandale, C. Coetzee and E. Raju, Disaster risk management status assessment at municipalities in South Africa, South African Local Government Association (SALGA), Pretoria, 2011.

L. S. Bosher, A. R. J. Dainty, P. M. Carrillo, J. Glass and A. D. F. Price, Attaining improved resilience to floods: A proactive multi-stakeholder approach, Disaster Prevention and Management 18 (1) (2009) 9-22.

W. J .W. Botzen, J. C. J. H. Aerts and J .C. J. M. van den Bergh, Willingness of homeowners to mitigate climate risk through insurance, Ecological Economics 68 (2009) 2265-2277. 
M. Brilly and M. Polic, Public perception of flood risks, flood forecasting, and mitigation, Nat Hazards Earth System Science 5 (3) (2005) 345-355.

R. A. Bradford et al, Risk perception-Issues for flood management in Europe, Natural Hazards and Earth System Science 12 (7) (2012).

P. Bubeck, W. J.W. Botzen, H. Kreibich and J. C. J. H. Aerts, Detailed insights into the influence of floodcoping appraisals on mitigation behavior, Global Environmental Change (2012),doi:10.1016/j.gloen vcha.2013.05.009.

R. J. Burby, Cooperating With Nature: Confronting natural hazards with land use planning for sustainable communities, United States: Joseph Henry Press, 1998a.

R. J. Burby, Natural Hazards and Land Use in $A n$ Introduction in Cooperating With Nature: Confronting Natural Hazards With Land Use Planning for Sustainable Communities, ed. R.J. Burby (United States: Joseph Henry Press, 1998b). pp. 1-28.

D. W. Cash and S. Moser, Linking global and local scales: designing dynamic assessment and management processes, Global Environmental Change (10) (2000) 109-120.

R. B. Cattell, The scree test for the number of factors, Multivariate Behavioral Research 1 (1966) 245-276.

S. L. Cutter, Living with Risk: The Geography of Technological Hazards, New York: Edward Arnold, 1993.

H. Chongfu, Multiple Internet of Intelligences for Risk Analysis, Journal of Risk Analysis and Crisis Response 4 (2) (June 2014) 61-71.

B. De. Marchi, A. Scolobig, G. Delli Zotti Del and M. Zotto, Risk construction and social vulnerability in an Italian Alpine Region, floodsite report, 2007.

N. Dufty, A new approach to community flood education, The Australian Journal of Emergency Management 23 (2) (2008).

H. A. Elliott et al., Improving Flood Warning -Which Way Forward?, The Australian Disaster Conference Canberra, 2003.

F. Ellis, Survey article: Household strategies and rural livelihood diversification, Journal of Development Studies 35 (1) (1998)1-38.

C. E. Faupel, S. P. Kelley and T. Petee, The impact of disaster education on household preparedness for hurricane Hugo, International Journal of Mass Emergencies and Disaster 10 (1) (1992) 5-24.

J. K. Fielding Gray, K. Burningham and D. Thrush, Flood warning for vulnerable groups: secondary analysis of flood data, Environment Agency R and D Report W5C-018/2.Environment Agency, Bristol, UK, (2005).

C. Folke, Freshwater and resilience: a shift in perspective. Philosophical Transaction of Royal Society, London Series B 358 (2003) 2027-36.

A. Gissing, M. Morgan and C. Ronan, Planning for the Inevitable- Emergency Planning for Floods in New South Wales, Proceedings of the 47th Floodplain Management Conference, Gunnedah, 2007.

T. Grothmann and F. Reusswig, Household at risk of flooding: Why some residents take precautionary action while others do not, Natural Hazards $\mathbf{3 8}$ (2006) 101-120.

T. Grothmann and A. Patt, Adaptive capacity and human cognition: the process of individual adaptation to climate change, Global Environmental Change Part A15 (3) (2005) 199-213.

J. Harvatt, J. Petts and J. Chilvers, Understanding householder responses to natural hazards: Flooding and sea level rise comparisons, Journal of Risk Research 14 (1) (2011) 63-83 doi:10.1080/1366 987 7.2010 .503935 .

A. Heidari, Structural master plan of flood mitigation measures, Natural Hazards and Earth System Sciences 9 (2009) 61-75.

J. H. Heinz, III. The hidden costs of coastal hazards: Implications for risk assessment and mitigation. Center for Science, Economics, and the Environment (Washington, DC, Island Press, 2000), pp. 252.

R. Hertwig, G. Barron, E. U, Weber and I. Erev, Decisions from experience and the effect of rare events, Psychological Science 15 (2004) 534-539.

M. Ho, D. S. Shaw, Lin and Y. Chiu, How do disaster characteristics influence risk perception? Risk Analysis 28 (3) (2008) 635-643.

H. Hung-Chih, The attitude towards flood insurance purchase when respondents' preferences are uncertain: A fuzzy approach, Journal of Risk Research 12 (2009) 239-258, doi:10.1080/13669 870802497702.

E. L. Jackson, Response to earthquake hazard: The west coast of North America, Environment Behavior 13(4) (1981) 387- 416.

G. Kaiser, S. Reese, H. J. Markau and H. Sterr, Public Perception of coastal flood defense and participation in coastal flood defense planning unpublished final report, 2004.

D. Keogh, A. Apan, S. Mushtaq, D. King and M. Thomas, Resilience, vulnerability, and adaptive capacity of an inland rural town prone to flooding: A climate change adaptation case 3 studies of Charleville, Queensland, Australia. Natural Hazards 59 (2011) 699-723.

A. Kirschenbaum, Disaster preparedness: A conceptual and empirical reevaluation, International Journal of Mass Emergencies and Disasters 20 (2002) 5-28.

R. J. T. Klein, R. J. Nicholls and F. Thomalla, The resilience of coastal megacities to weather-related hazards: a review in Building Safer Cities: The Future of Disaster Risk, eds. A. Kreimer., M. Arnold, A. Carlin, (Disaster Risk Management Series No. 3, World Bank, Washin- gton, DC, USA, 2003). pp. 101-120.

J. K. Lazo, D. M. Waldman and B. H. Morrow, Household Evacuation Decision Making and the Benefits of Improved Hurricane Forecasting: Developing a Framework for Assessment, American Meteorological Society 25 (2010) 207-219 doi: $10.1175 / 2009$ WAF 2222310.1.

C. Lengnick-Hall and T. Beck, Adaptive Fit Versus Robust Transformation: How Organizations Respond to Environmental Change, Journal of Management 31 (5) 738-757 (2005). 
M. K. Lindell and R. W. Perry, Households Adjustment to Earthquake Hazard, Environment Behavior 32 (2000) 590-630.

C. W. Lin, S. T. Lu, T. S. Shih, W. H. Lin, Y. C Liu and P. T. Chen, Active faults of Central Taiwan, Centre for Geological Survey 21(2008) 148.

D. Loseke, Thinking about Social Problems: An Introduction to Constructionist Perspectives. New York: Aldine de Gruyter, 1999.

P. Longstaff, Security, resilience, and communication in unpredictable environments such as terrorism, natural disasters, and complex technology. Syracuse, NY: Author, 2005.

J. Ludy and G. Kondolf, Flood risk perception in lands "protected" by 100-year levees, Natural Hazards 61 (2012) 829-842.

B. Maguire and P. Hagan, Disasters and communities: understanding social resilience, The Australian Journal of Emergency Management 22 (2007)16-20.

A. J. Milne, H. H. Wollford, J. Masonand and E. Hatzidimitriadou, Early diagnosis of dementia by GPs: an exploratory study of attitudes, Aging and Mental Health 4 (2000) 292-300.

R. Miceli, I. Sotgiu and M. Settanni, Disaster preparedness and perception of flood risk: A study in an Alpine valley in Italy, Journal of Environment Psychology 28 (2008) 164-173.

D. Mileti, Disasters by Design: A Reassessment of Natural Hazards in the United States. Washington, DC: Joseph Henry Press, 1999.

A. Niehof, The significance of diversification for rural livelihood systems, Food Policy 29(2004) 321-338.

F. H. Norris and S. A. Murrell. Prior experience as a moderator of Disaster impact on anxiety symptoms in older Adults, American Journal of Community Psychology 16 (1998) 665-683.

H. Nyakundi, S. Mogere, I. Mwanzo and A. Yitambe, Community perceptions and response to flood risks in Nyando District, Western Kenya, Jàmbá. Journal of Disaster Risk Studies 3(1) (2010) 346-365. doi: 10.4102 /jamba.v3i1.35.

D. Paton, L. Smith, D. Johnston, M. Johnston and K. Ronan, Developing a model to predict the adoption of natural hazard risk reduction and preparatory adjustments (Research Project No. 01-479) EQC Research Report (2003).

R. I. Palm, Public response to earthquake hazard information, Annals of the Association of American Geographers 71(3) (1981)389-399.

E. Pagneux, G. Gisladottir and S. Jonsdottir, Public perception of flood hazard and flood risk in Iceland: A case study in a watershed prone to ice-jam floods, Nat. Hazards 58 (2011) 269-287.

D. Paton, J. McClure and P. T. Burgelt, Natural hazard resilience: the role of individual and household preparedness in Disaster resilience: An integrated approach, eds. D. Paton and D. Johnston, (Springfield, Illinois: Charles C. Thomas 2006). pp.105-124.

R. W. Perry and M. K. Lindell, The psychological consequences of natural disaster: A review of research on American communities, Mass Emergencies 3 (1978) 105-115.
T. Plapp and U. Werner, Understanding risk perception from natural hazards: examples from Germany in RISK 21, Coping with risks due to natural hazards in the $21^{\text {st }}$ century, eds. W. J. Amman., S. Dannenmann and L. Vulliet, (Proceeding of Risk 21 workshop 2004, Taylor and Francis, London, 2006) pp. 101108.

R. Raaijmakers, J. R. Krywkow and A. van der Veen, Flood risk perceptions and spatial multi-criteria analysis: An exploratory research for hazard mitigation, Nat. Hazards 46 (2008) 307-322.

B. Reid, W. Smit, B. O. Caldwell and S. Belliveau, Vulnerability and adaptation to climate risks in Ontario agriculture, Mitigation Adaptation Strategy Global Change 12 (2007) 609-637.doi10.1007/s 11027-006-9051-8.

R. W. Rogers, Cognitive and physiological processes in fear appeals and attitude change: A revised theory of protection motivation in Social Psychophysiology, eds. J. Cacioppo and R. Petty (New York: Guilford Press, 1983).

I. Ruin, J. C. Gaillard and C. Lutoff, How to get there? Assessing motorists' flash flood risk perception on daily itineraries, Environment Hazards 7(3) (2007) 235-244, doi:10.1016/j. envhaz.2007.07.005.

C. Saavedra and W. Budd, Climate change and environmental planning: Working to build community resilience and adaptive capacity in Washington State, USA, Habitat International 33(3) (2009) 246-252.

M. Siegrist and H. Gutscher, Natural Hazards and Motivation for Mitigation Behavior: People Cannot Predict the Affect Evoked by a Severe Flood, Risk Analysis 28 (3) (2008) 771-778,doi: 10.1111/j. 15396924.2008.01049.x.

P. Slovic, Perception of Risk Reflections on the Psychometric Paradigm in Social Theories of Risk, eds. S. Krimsky., and D. Golding Praeger, (Westport 1992)pp.117-152.

P. Slovic, M. L. Finucane, E. Peters and D.G. MacGregor, Risk as analysis and risk as feelings: Some thoughts about affect, reason, risk, and rationality, Risk Analysis 24 (2) (2004) 311-322.

B. Smit and J. Wandel, Adaptation, Adaptive Capacity and Vulnerability, Global Environmental Change 16 (2006) 282-292.

D. I. Smith, J. W. Handmer, J. M. McKay, M. A. D. Switzer and B. J. Williams, Non-Destructive Measures in Australian Urban Floodplain Management: Barriers and Recommendations, The Australian Journal of Emergency Management 11(2) (1996) 51-56.

R. Srivastava and L. Laurian, Natural Hazard Mitigation in Local Comprehensive Plans: The Case of Flood, Wildfire and Drought Planning, Disaster Prevention and Management: An International Journal 15 (3) (2006) 461-483.

M. N. Srinivas, Caste, its twentieth century avatar, New York, Penguin Books (1996).

R. A. Stablling. Promoting Risk: Constructing the Earthquake Threat. New York: Aldine de Gruyter, 1995. 
S. Tapsell, The health effects from fluvial flooding. Report to the Environment Agency, Flood Hazard Research Centre, Enfield, 2001.

L. L. Thurstone, Multiple factor analysis. Chicago: University of Chicago Press, 1947.

K. Tierney and M. Bruneau, Conceptualizing and measuring resilience: A key to disaster loss reduction.TR News, May-June 2007, 14-1.

P. Timmerman, Vulnerability, Resilience and the Collapse of Society: A Review of Models and Possible Climatic Applications. Institute for Environmental Studies, University of Toronto, Canada, 1981.

E. L. Tompkins and W. N. Adger, Responding to climate change: Implications for development, id21 insights 53 (2004) 4-4.

R. H. Turner, J. M. Nigg and D. H. Paz, Waiting for disasters: earthquake watch in California. University of California Press, Berkeley, California, USA, 1986.
UNISDR, Global Assessment Report on Disaster Risk Reduction, United Nations International Strategy for Disaster Reduction Secretariat: Geneva, 2009.

A. Vari and Z. Ferencz, Flood research from the social perspective: the case of the Tisza River Hungary in Flood Research: Le Point de la Recherche sur les Crues, eds. I. Tchiguirinskaia., Ni. Ni. Thein and K. P. Hubert (Frontiers in IAHS Press, 2006) pp.155172.

B. Walker et al., Resilience, adaptability, and transformability, Ecology and Society 9 (2) (2004) 5,http://www. Ecology andsociety.org/vol9/iss2/art5.

G. Wachinger and O. Renn, Risk perception and natural hazards, CapHaz-Net WP3 Report, DIALOGIK Non-Profit Institute for Communication and Cooperative Research, Stuttgart,2010klk, (2010), http://caphaz-net.org /outcomes- results/CapHazNet WP3 Risk- Percep tion.pdf.

N. D. Weinstein, Effects of personal experience on selfprotective behavior, Psychological Bulletin 105 (1989) 31-50. 